Working Paper

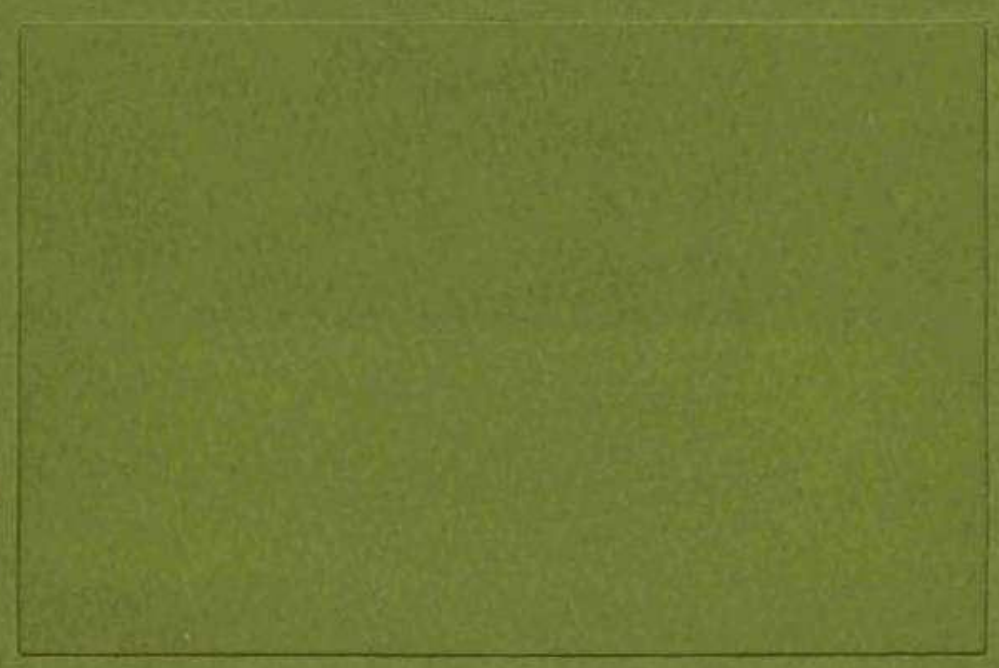

Research Department Federal Reserve Bank of Minneapolis

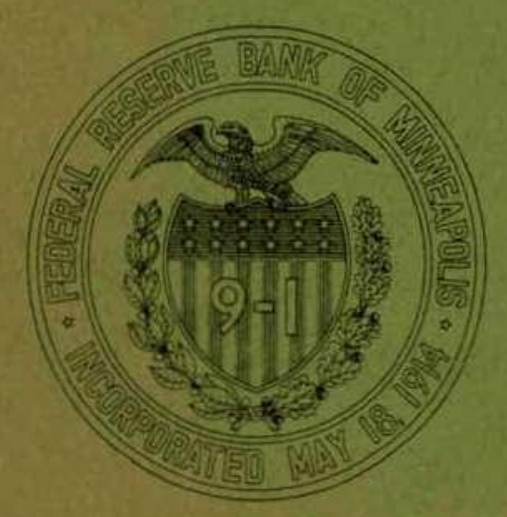


Federal Reserve Bank of Minneapolis

Research Department

\section{TIME CONSISTENCY AND POLICY}

V. V. Chari, Patrick J. Kehoe and Edward C. Prescott*

Working Paper 365

Revised February 1988

NOT FOR DISTRIBUTION

WITHOUT AUTHOR APPROVAL

*Chari, Federal Reserve Bank of Minneapolis; Kehoe, Federal Reserve Bank of Minneapolis and University of Minnesota; Prescott, Federal Reserve Bank of Minneapolis and University of Minnesota.

The views expressed herein are those of the authors and not necessarily those of the Federal Reserve Bank of Minneapolis or the Federal Reserve System. This paper is preliminary and is circulated to stimulate discussion. It is not to be quoted without the authors' permission. 
The design of fiscal and monetary policy is a central concern in aggregative economics. The public finance tradition stemning from Ramsey (1927) provides a useful framework for thinking about optimal policy design. Ramsey studied a static, representative consumer economy with many goods. A government requires fixed amounts of these goods which are purchased at market prices and financed by proportional excise taxes. Given the excise taxes, prices and quantities are determined in a competitive equilibrium. The government's problem is to choose tax rates to maximize the welfare of the representative consumer. It is straightforward to extend this formulation to study fiscal policy in dynamic models with uncertainty by reinterpreting the goods in the static problem as state contingent commodities. In this context a policy for government in this context is a rule specifying state contingent tax rates. Given a policy, competitive equilibrium prices and allocations are defined as functions of the state of the economy. The design problem is to choose a policy which maximizes a social welfare function defined over the resulting competitive allocations. An optimal policy together with the resulting competitive equilibrium is a Ramsey equilibrium.

In the Ramsey equilibrium, consumers make decisions once and for all at the beginning of time. However, this equilibrium can also be interpreted as a one-time choice of government policy with consumers making decisions sequentially given the policy. This interpretation is certainly appropriate in environments where societies have access to a commitment technology to bind the actions of future governments. In many situations it is more appropriate to think of policies as being chosen at each date with no ability on society's part to commit to future policies. In such environments, one is tempted to conclude that the resulting policy choices coincide with the Ramsey policies. This is not the case. Consider the policy choice problem at some date 
$t$ assuming that policies and allocations coincide with the Ramsey equilibrium until that date. The solution to the new policy choice problem typically does not coincide with the Ramsey policies from that date onward. Kydland and Prescott (1977), Prescott (1977), Calvo (1978), and Fischer (1980) showed that this dynamic inconsistency of the Ramsey policies is pervasive in models of fiscal and monetary policy. This dynamic inconsistency means that the Ramsey policies are simply irrelevant in a world without commitment. Clearly, rational individuals will not base their decisions on the Ramsey policies if a different set of policies will be chosen in the future.

A solution to the design problem without commitment must therefore require that policies be sequentially rational. That is, the policy rules must maximize the social welfare function at each date given that private agents behave optimally. Likewise, optimality on the part of private agents requires that they forecast future policies as being sequentially rational for society. A sequence of policy rules, allocations, and prices satisfying these conditions is a time consistent equilibrium. We say there is a time consistency problem if the Ramsey and time consistent equilibria are different. It is worth remarking that time consistency problems can arise in individual decision problems when preferences change over time (see Strotz 1955). We therefore restrict ourselves to situations where preferences are time consistent in Strotz's sense. The source of time consistency problems cannot then lie in such preferences.

In section 1 , we argue that the source of time consistency problems lies in conflict among agents. In fact, in a team environment where the objectives of all agents are identical we show that there can be no time consistency problems. Most models of fiscal and monetary policy use a representative agent construct and a social welfare function which coincides with 
the representative agent's utility function. The representative agent formulation should not mislead us into thinking that the individuals in this economy form a team. The objectives of individuals do not coincide because in such models each individual cares only about his own consumption. Consequently, even in representative agent models there are generally time consistency problems. We explore the precise nature of the time consistency problem in two examples.

The classic illustrations of the time consistency problem are capital taxation and default on government debt. In section 2 we analyze a variant of Fischer's (1980) model of capital taxation and in section 3 we analyze a variant of Prescott's (1977) debt default model. In section 4 we provide a complete analysis of the capital taxation problem with an infinite horizon. We define and characterize time consistent equilibria for these examples.

Our formulation of time consistent equilibria, based on Chari-Kehoe (1987a and b), allows allocations and policies to depend on the entire history of past decisions by governments as well as past aggregate (or average percapita) allocations. Thus, policies and allocations are defined as historycontingent functions. This break from the general equilibrium tradition of considering equilibria which are state contingent functions is essential in imposing the requirement of sequential rationality. Both governments and consumers must forecast how current decisions affect future outcomes. Allowing for history contingent function solves this forecasting problem.

For finite horizon models sequential rationality implies that this problem is solved by backward induction. For infinite horizon models such a procedure is no longer available. Indeed for infinite horizon models there is typically a large set of time consistent equilibria which are quite difficult to characterize. However, it turns out that the set of allocations that can 
result from time consistent equilibria is fairly easy to characterize. In section 4 we provide a simple set of inequalities which can be used to characterize such allocations. We show that with sufficiently little discounting even the Ramsey allocations can be supported by some time consistent equilibrium.

The policy plans and allocations rules we use to support the large set of time consistent allocations are closely related to "trigger" strategies of repeated games (see, for example, Friedman, 1971). Loosely speaking, for any given pair of policy and allocation sequences, the history-contingent policy and allocation rules used to support them specify continuation with these sequences as long as there has been no deviation. If there has been a deviation, revert to the single-period time consistent equilibrium forever. While such rules resemble the trigger strategies of games it is important to point out that in our models private agents behave competitively and not strategically. In particular, private agents do not collude to "punish" the government. Rather, after a deviation private agents choose the single period time consistent allocations because they forecast that the government will choose the single period time consistent policy. The government in turn, taking the aggregate allocation rule for private agents as given, optimally chooses this policy. Because of this feature some of our results differ from the related results in repeated games.

\section{A overview of the time consistency problem}

In this section we formulate policy design as a simple social choice problem and use this framework to provide an overview of the time consistency problem. We compare the equilibria of an environment with commitment to those of an environment without commitment. We formalize commitment as a particular timing scheme for decision making. Society first chooses a policy once-and- 
for-all and after this, private agents choose their actions. In the environment without commitment decisions are made sequentially. An example of such a timing scheme in a multiperiod economy is that first private agents choose their first period actions, then the government chooses its first period policy then private agents choose their second period actions and so on. For ease of exposition we consider a one-period economy. In this case the two timing schemes are particularly simple. With commitment the government first sets policy, then private agents make their decisions. Without commitment, private agents first make their decisions and then the government sets policy. It will be clear that all of the results extend to multiperiod economies.

Throughout the section we consider special cases of the following environment. There is a society consisting of $n$ private agents. Each agent $i$ $(i=1, \ldots, n)$ chooses an action $x_{i}$ from a set of actions $x_{i}$. The vector of actions $x=\left(x_{1}, \ldots, x_{n}\right)$ is called an allocation. Society chooses a policy $\pi$ from a set of policies $\pi$. The preferences of each private agent are given by a utility function $U^{i}(x, \pi)$, and society's preferences are given by $S(x, \pi)$. Initially we model allocations as the outcome of a Nash equilibrium and later as the outcome of a competitive equilibrium.

It turns out that the preferences of private agents and society play a critical role in determining if the allocations with and without comitment coincide--that is, in determining if there is a time consistency problem. We first show that if all agents' preferences coincide with those of society, then there can be no time consistency problem. We then give necessary conditions for there to be a time consistency problem. We illustrate these conditions is a simple model of inflation and unemployment. 


\subsection{Team environments}

A team is defined to be a group of individuals whose objectives are identical. We show that in a team environment there can be no time consistency problem. Specifically, suppose that each agent's preferences coincides with those of society. Let the utility function of each agent $i$ over the whole vector $x$ and the policy $\pi$ be given by some strictly concave, twice differentiable function $U(x, \pi)$. Let this function also be the social objective function. Notice that together the private agents and society form a team. While team members control only their own actions, they all choose these actions to achieve a common goal.

Under commitment, society chooses a policy $\pi$ and then given this policy, private agents all simultaneously choose $x_{i}$. First consider the choice of private agents, given some policy $\pi$. Each agent $i$ faced with a policy $\pi$ and taking as given the decisions $x_{-i}=\left(x_{1}, \ldots, x_{i-1}, x_{i+1}, \ldots, x_{n}\right)$ of all other agents, solves

$$
\max _{\mathrm{x}_{i}} \mathrm{U}(\mathrm{x}, \pi)
$$

Assuming an interior solution, the first-order condition is

$$
\frac{\partial U}{\partial x_{i}}=0
$$

For a given policy, $\pi$, an equilibrium for private agents is a vector $x$ such that for each $i, x_{i}$ solves (1.1), given $x_{-i}$. For any such policy, $\pi$, denote the resulting equilibrium allocations by $X(\pi)$. For simplicity, assume that for each $\pi$ there is a unique equilibrium and that the resulting function $X(\pi)$ is differentiable. This function $X(\cdot)$ is called the outcome function.

Society's problem, then, is to choose a policy $\pi$ to maximize its objective function taking the outcome function $X(\cdot)$ as given. That is, society solves 
$\max _{\pi} U(X(\pi), \pi)$.

Assuming an interior solution, the first-order condition for society is

$$
\sum_{i=1}^{n} \frac{\partial U}{\partial x_{i}} \frac{\partial X_{i}}{\partial \pi}+\frac{\partial U}{\partial \pi}=0
$$

We then have the following definition:

An equilibrium with commitment is a policy $\pi^{*}$ and an outcome function $X(\cdot)$ that satisfy

- Maximization for society. Given $X(\cdot)$, the policy $\pi^{*}$ solves $(1.3)$.

- Private equilibrium. For each $\pi$, the outcome $X(\pi)$ is an equilibrium for private agents.

Notice that the private decisions actually taken in such an equilibrium are given by $x^{*}=X\left(\pi^{*}\right)$.

Without a commitment technology, the equilibrium is somewhat different. In particular, private agents first choose a vector $x$ and then society chooses a policy $\pi$. Given some allocation $x$, the problem faced by society is

$$
\max _{\pi} U(x, \pi)
$$

The first-order condition for society is

$$
\frac{\partial U}{\partial \pi}=0
$$

Assume that for each vector $x$, the policy $\pi$ defined by $(1.6)$ is unique and that the resulting policy rule, $\Pi(x)$, is differentiable. In this equilibrium each private agent $i$ takes as given the policy rule $\Pi(\cdot)$ and the decisions of other private agents $x_{-i}$ and solves

$$
\max _{x_{i}} U(x, \Pi(x))
$$


The first-order condition for each agent $i$ is

$$
\frac{\partial U}{\partial x_{i}}+\frac{\partial U}{\partial \pi} \frac{\partial I}{\partial x_{i}}=0
$$

(Notice that we let each private agent take account of the effect his action has on the policy chosen by society. When the number of private agents is large, this effect will be small; in the limit, it it will be zero.) We then have the following definition:

An equilibrium without commitment is a vector of private decisions $x^{*}$ and a policy rule $\Pi(\cdot)$ that satisfy

- Private equilibrium. Given $x_{-i}^{*}$ and $\Pi(\cdot), x_{i}^{*}$ solves $(1.7)$.

- Maximization for society. For any $x$, the policy rule $\pi(\cdot)$ solves $(1.5)$.

We can now compare the equilibrium outcomes with and without commitment. Combining (1.2) and (1.4), we have that the equilibrium outcome with commitment is completely characterized by

$$
\frac{\partial U}{\partial \pi}=0 \text { and } \frac{\partial U}{\partial x_{i}}=0 \text {, for all } i
$$

Combining (1.6) and (1.8) we have that the equilibrium outcome without commitment is characterized by

$$
\frac{\partial U}{\partial x_{i}}=0, \text { for all } i \text {, and } \frac{\partial U}{\partial \pi}=0
$$

Notice that (1.9) and $(1.10)$ are identical and that either set of equations are the first-order conditions to

$$
\max _{x, \pi} U(x, \pi) .
$$


By strict concavity, the solution to this problem is unique and hence we have established the following proposition:

Proposition 1 (No time consistency problem in a team environment)

If all agents have the same objective function as society the equilibrium allocations and policies with and without commitment are identical.

Thus in order for there to be a time consistency problem there needs to be some conflict of interests either between society and private agents or among private agents themselves. We turn now to such situations.

\subsection{Benevolent agents and a self-interested society}

A variety of papers in the literature have examined situations in which the preferences of society do not coincide with those of private agents. (For example, see Kydland and Prescott, 1977, Barro and Gordon, 1983, and Rogoff, 1988.) In our framework we model such a situation by letting each private agent's objective function be $U(x, \pi)$ and letting society's objective function be some other function, say $S(x, \pi)$. For this specification an analysis similar to the team environment analysis gives that an equilibrium with commitment is summarized by

$$
\frac{\partial U}{\partial x_{i}}=0, \text { for all } i
$$

and

$$
\sum_{i=1}^{n} \frac{\partial S}{\partial x_{i}} \frac{\partial X_{i}}{\partial \pi}+\frac{\partial S}{\partial \pi}=0
$$

Likewise, an equilibrium without commitment is summarized by

$$
\frac{\partial S}{\partial \pi}=0
$$


and

$$
\frac{\partial U}{\partial x_{i}}+\frac{\partial U}{\partial \pi} \frac{\partial I}{\partial x_{i}}=0, \text { for all i. }
$$

It is clear that, in general, the solutions to these two sets of equations will be different.

One justification for assuming that the preferences of society do not coincide with those of its constituent agents is that policy choices are made by a self-interested government. As we have seen, the discrepancy in objectives between such a government and the members of society induces a conflict of interests that can lead to a time consistency problem. It is not clear to us why the preferences of society do not reflect the preferences of its constituents. Thus the time consistency problems just described do not seem an interesting way to model social choice in democratic societies.

\subsection{Self-interested agents and a benevolent society}

We now consider an environment in which the preferences of each private agent can differ. In particular, let the preferences of agent $i$ be given by $U^{i}(x, \pi)$. Notice that since each agent's utility is affected by other agents decisions, this is an economy with external effects. We model society as being benevolent in the sense that it solves a Pareto problem by maximizing

$$
\sum_{i=1}^{n} \lambda_{i} U^{i}(x, \pi)
$$

for some set of welfare weights $\lambda=\left(\lambda_{1}, \ldots, \lambda_{n}\right)$.

With commitment, the first-order condition for each agent is

$$
\frac{\partial U^{i}}{\partial x_{i}}=0
$$


and the first-order condition for society is

$$
\sum_{i=1}^{n} \lambda_{i} \sum_{j=1}^{n} \frac{\partial U^{i}}{\partial x_{j}} \frac{\partial X}{\partial \pi}+\frac{\partial U^{i}}{\partial \pi}=0 .
$$

Likewise, without commitment the first-order condition for society is

$$
\sum_{i=1}^{n} \lambda_{i} \frac{\partial U^{i}}{\partial \pi}=0
$$

and the first-order condition for an agent $i$ is

$$
\frac{\partial U^{i}}{\partial x_{i}}+\frac{\partial U^{i}}{\partial \pi} \frac{\partial \Pi}{\partial x_{i}}=0 .
$$

Notice that, in general, these two solutions will differ so that when there are externalities there is typically a time consistency problem.

\subsection{Representative agent models}

A particularly interesting class of social choice problems arises in competitive equilibrium models with a representative agent. It turns out that such problems can be represented in our general social choice framework. For this class of problems the objective functions of agents are

$$
U^{i}(x, \pi)=U\left(x_{i}, \bar{x}, \pi\right)
$$

where $\bar{x}=\frac{1}{n} \sum_{i=1}^{n} x_{i}$ denotes the average or aggregate per capita allocations. The objective function of society is

$$
S(x, \pi)=\sum_{i=1}^{n} U\left(x_{i}, \bar{x}, \pi\right) .
$$

Modeling private agents as competitive amounts to assuming that each agent i takes both the aggregate allocation $\bar{x}$ and the policy $\pi$ as given and that $\Pi$ is constrained to depend only on the aggregate allocation $\bar{x}$. In the case with commitment the first-order conditions reduce to 


$$
\frac{\partial U^{i}}{\partial x_{i}}=0, \text { for all } i
$$

and

$$
\sum_{i=1}^{n} \frac{\partial U^{i}}{\partial \bar{x}} \frac{\partial \bar{X}}{\partial \pi}+\frac{\partial U^{i}}{\partial \pi}=0 .
$$

In the case without commitment the first-order conditions are

$$
\sum_{i=1}^{n} \frac{\partial U^{i}}{\partial \pi}=0
$$

and

$$
\frac{\partial U^{i}}{\partial x_{i}}=0, \text { for all } i
$$

It is clear that, in general, the solutions to these problems are different. Notice that if the utility functions did not depend on the aggregate allocation $\bar{x}$, then the solutions to these problems would be the same. Dependence of the utility functions on aggregate allocations induces a subtle source of conflict among agents. We next illustrate the nature of this conflict in a simple model of inflation. We consider more complicated examples in sections 2 and 3.

\subsection{Conflict among agents in a simple model of inflation}

Perhaps the most widely used example in the time consistency literature is a Phillips curve model of inflation and unemployment. Kydland and Prescott (1977) first used this model to illustrate the problem of time consistency. Barro and Gordon (1983) and Rogoff (1988) have elaborated on the basic model. The idea is that unanticipated inflation provides benefits to society while anticipated inflation is costly. Within our social choice framework, we can model these features as follows. 
Each private agent chooses the (log of) his nominal wage $x_{i}$. Society, which here is identified with the monetary authority, chooses the (log of) the price level $\pi$. The aggregate $\bar{x}=1 / n \sum_{i=1}^{n} x_{i}$ is the average nominal wage in the economy. The utility function of private agents is given by

$$
U^{i}(x, \pi)=U\left(x_{i}-\pi, \bar{x}-\pi, \pi\right)
$$

while the utility function of the monetary authorities is given by

$$
S(x, \pi)=\sum_{i=1}^{n} U\left(x_{i}-\pi, \bar{x}-\pi, \pi\right)
$$

As usual, we consider two kinds of commitment technologies. The first-order conditions with commitment reduce to

$$
U_{1}\left(x_{i}-\pi, \bar{x}-\pi, \pi\right)=0 \text {, for all } i
$$

and

$$
\sum_{i=1}^{n}\left[U_{2}\left(x_{i}-\pi, \bar{x}-\pi, \pi\right)\left[\frac{\partial \bar{x}}{\partial \pi}-1\right]+U_{3}\left(x_{i}-\pi, \bar{x}-\pi, \pi\right)\right]=0 .
$$

The first order conditions without commitment reduce to

$$
U_{1}\left(x_{i}-\pi, \bar{x}-\pi, \pi\right)=0
$$

and

$$
\sum_{i=1}^{n}\left[U_{3}\left(x_{i}-\pi, \bar{x}-\pi, \pi\right)-U_{2}\left(x_{i}-\pi, \bar{x}-\pi, \pi\right)\right]=0 \text {. }
$$

In this type of model it is common to assume that for a fixed price level $\pi$ and aggregate nominal wage $x_{i}$, the utility of agent $i$ is maximized by setting the nominal wage equal to the price level plus a constant $k$. Thus $U_{1}(\cdot)=0$ when the first argument equals $k$. One rationalization for this is that a real wage higher than the one given by the constant $k$ leads to lower employment and hence lower utility. 
Since $U_{1}(\cdot)=0$ when the real wage $x^{i}-\pi$ equals $k$, in an equilibrium with commitment $\partial \bar{X} / \partial \pi=1$. It follows from equations (1.11) and $(1.12)$ that the solutions to the two problems are different. Notice that it is crucial for society to care about the second argument, $\bar{x}-\pi$, that is, the average real wage in the economy. If the utility functions of private agents or society did not depend upon this argument, then the solutions would be identical. Barro (1985) and Rogoff (1988) recognize the importance of this assumption. They argue that unanticipated inflation provides social benefits if the natural rate of unemployment exceeds the socially optimal level due to the presence of externalities or distorting taxation. Since these features are not modeled it is hard to assess the validity of the argument. Suffice it to say, some such force must be present if this model is to generate a time consistency problem.

\subsection{Summary}

To summarize this overview section, we have made three main points: First, time consistency cannot arise in a team environment. Second, time consistency problems typically arise whenever governments do not maximize the welfare of private agents. Third, even if governments are benevolent, conflicts among private agents can cause time consistency problems. In the sections that follow we consider two examples that investigate how the interactions between external effects and the timing of decisions generate time consistency problems.

\section{The capital taxation model}

In this section we consider a version of Fischer's (1980) capital taxation model, modified along the lines of Chari and Kehoe (1987a). Initially we consider a one-period version of the model. For this version we 
define and characterize the equilibria with and without commitment. We then show that these results immediately generalize to a finite-period version of the model. In section 4 we discuss the infinite horizon version of this model.

Consider an economy with a large number of identical consumers and a government. There is a linear production technology for which the marginal product of capital is a constant $R>1$ and the marginal product of labor is 1. Consumers make decisions at two distinct points in time, the first stage and the second stage. They make consumption-investment decisions at the first stage and consumption-labor supply decisions at the second stage. In particular, at the first stage consumers are endowed with w units of the consumption good from which they consume $c_{1}$ and save $k$. At the second stage each agent consumes $c_{2}$ and works $\ell$ units. Second-stage income, net of taxes, is $(1-\delta) R k$ $+(1-\tau) \ell$, where $\delta$ and $\tau$ denote the tax rates on capital and labor respectively. For simplicity we assume that first-stage consumption is a perfect substitute for second-stage consumption. A consumer, confronted with tax rates $\delta$ and $\tau$, chooses $\left(c_{1}, k ; c_{2}, l\right)$ to solve

$$
\max U\left(c_{1}+c_{2}, l\right)
$$

subject to

$$
\begin{aligned}
& c_{1}+k \leq \omega \\
& c_{2} \leq(1-\delta) R k+(1-\tau) \ell .
\end{aligned}
$$

If the tax rate on capital $\delta$ is set so that $(1-\delta) R=1$, the consumer is indifferent about the timing of consumption. We assume that in such a case, the consumer saves his entire endowment. 
The government sets proportional tax rates on capital and labor income to finance an exogenously given amount of second-stage per capita government spending $g$. The government's budget constraint is

$$
g \leq \delta R K+T L
$$

where $K$ and $L$ denote the per capita (or aggregate) levels of capital and labor. We assume that $g>R \omega$ so that even if consumers save entire endowments and the tax on capital is set equal to one, the government still needs to tax labor.

In what follows we adopt the notational convention that lowercase letters denote individual variables and uppercase letters, denote aggregate variables. This notation is used to emphasize what various agents take as given.

\subsection{Capital taxation with commitment}

In an economy with commitment, the government sets tax rates before private agents make their decisions. We call such a policy a full commitment policy. In this setup it is straightforward to define an equilibrium. Let $x_{1}$ $=\left(c_{1}, k\right)$ and $x_{2}=\left(c_{2}, l\right)$ denote an individual consumer's first-and secondstage allocations and let $x_{1}=\left(C_{1}, K\right)$ and $x_{2}=\left(C_{2}, L\right)$ denote the corresponding aggregate allocations. Let $\pi=(\delta, \tau)$ denote government policy. We have the following definition:

A full commitment equilibrium is an individual allocation $\left(x_{1}, x_{2}\right)$, an aggregate allocation $\left(\mathrm{X}_{1}, \mathrm{X}_{2}\right)$, and a tax policy $\pi$ that satisfy:

- Consumer maximization. Taking the tax policy $\pi$ as given, the individual allocations solve the consumer's problem (2.1). 
- Government budget constraint. At the aggregate allocation $\left(x_{1}, x_{2}\right)$, the policy $\pi$ satisfies the government budget constraint (2.2).

- Representativeness. The individual and aggregate allocations coincide, that is, $\left(x_{1}, x_{2}\right)=\left(x_{1}, x_{2}\right)$.

Given that the individual and aggregate allocations coincide, we can refer to such an equilibrium as a $(\pi, X)$ pair, where $X=\left(X_{1}, X_{2}\right)$. Let $E$ denote the set of policies $\pi$ for which an equilibrium exists. Assume that for each $\pi$ in $E$ there is a unique equilibrium allocation $X(\pi)$ associated with $\pi$. Let $S(\pi, X(\pi))$ denote the equilibrium value of utility under the policy $\pi$ so that

$$
S(\pi, X(\pi))=U\left(C_{1}(\pi)+C_{2}(\pi), L(\pi)\right)
$$

We say that a pair $(\pi, X)$ is a Ramsey equilibrium if $\pi$ solves

$$
\max _{\pi \in \mathrm{E}} S(\pi, X(\pi))
$$

and $X=X(\pi)$. We then have

\section{Proposition 2 (The Ramsey Equilibrium)}

The Ramsey equilibrium $(\pi, X)$ has first-stage allocations $C_{1}=0$ and $\mathrm{K}=\omega$ and a capital tax rate $\delta=(\mathrm{R}-1) / \mathrm{R}$.

Proof. If the tax on capital is such that $(1-\delta) R \geq 1$, then each consumer saves his entire endowment, while if $(1-\delta) R<1$, then the consumer saves nothing. Thus the tax on capital acts like a lump-sum tax when it is selected at any level less than or equal to $(R-1) / R$. Clearly it is optimal to raise as much revenue as possible from this tax. Since $g>R \omega$, government spending is greater than the maximal possible revenues from this capital tax, so it is optimal to set $\delta=(R-1) / R$. Faced with this tax, consumers save their entire endowment. The tax rate on labor is then set so as to raise the rest of the needed revenues. 0 


\subsection{Capital taxation without commitment}

Formally, the lack of commitment is modeled by assuming that the government does not set policy until after consumers have made their firststage decisions. Thus the timing is (1) consumers make first-stage decisions, (2) the government sets tax policy, (3) consumers make second-stage decisions. In this setup, the government's tax rates can vary depending on what the aggregate first stage decisions have been. Thus, a government policy is no longer a pair of tax rates $\pi=(\delta, \tau)$ but rather a specification of tax rates for every possible $X_{1}$, say $\sigma\left(X_{1}\right)=\left(\delta\left(X_{1}\right), \tau\left(X_{1}\right)\right)$. To keep the distinction between these clear, we call the function a a policy plan and we call a specific set of tax rates $\pi$ simply a policy.

Each consumer's second-stage decisions depend on the first-stage decisions $x_{1}$, the aggregate first-stage decisions $x_{1}$, and the tax policy selected. Thus, a consumer's second-stage decisions are described by a pair of functions, say $f_{2}\left(x_{1}, X_{1}, \pi\right)=\left(c_{2}\left(x_{1}, X_{1}, \pi\right), \ell\left(x_{1}, X_{1}, \pi\right)\right)$. We call $f_{2}$ a second-stage allocation rule to distinguish it from a particular second-stage allocation $x_{2}$. Likewise, the aggregate allocation rule $F_{2}$ is defined as a function of the aggregate first-stage decision $X_{1}$ and the policy $\pi$ and is denoted by $\mathrm{F}_{2}\left(\mathrm{X}_{1}, \pi\right)$.

An equilibrium in this environment is defined recursively. First, a second-stage competitive equilibrium is defined, given the history of past decisions by consumers and the government. We consider symmetric histories $\left(x_{1}, x_{1}, \pi\right)$ for which the individual allocation $x_{1}$ equals the aggregate allocation $x_{1}$. The resulting allocation rules are used to define the problem facing the government. Next, the first-stage competitive equilibrium is defined. Combining all of these gives an equilibrium which we call a time consistent equilibrium. We define a second-stage competitive equilibrium as 
A competitive equilibrium at the second stage, given the history $\left(x_{1}, x_{1}, \pi\right)$, is a set of individual and aggregate allocation rules $f_{2}$ and $F_{2}$ such that the following conditions are satisfied:

- Consumer maximization. Taking as given the history $\left(x_{1}, x_{1}, \pi\right)$, the individual allocation rule $\mathrm{f}_{2}\left(\mathrm{x}_{1}, \mathrm{x}_{1}, \pi\right)$ solves

$$
\max _{c_{2}, l} U\left(c_{1}+c_{2}, l\right)
$$

subject to $c_{2} \leq R(1-\delta) k+(1-\tau) \ell$.

- Government budget constraint. The aggregate allocation rule $\mathrm{F}_{2}\left(\mathrm{X}_{1}, \pi\right)$ satisfies $\mathrm{g} \leq \mathrm{R} \delta \mathrm{K}+\tau \mathrm{L}$.

- Representativeness. $f_{2}\left(X_{1}, X_{1}, \pi\right)=F_{2}\left(X_{1}, \pi\right)$.

Since this equilibrium is defined for each history, we can summarize it by the function $\mathrm{F}_{2}\left(X_{1}, \pi\right)$.

Next consider the situation of the government. Given the past aggregate decisions $\mathrm{X}_{1}$ and knowing that future decisions are selected according to the rule $F_{2}\left(X_{1}, \pi\right)$, the government selects a policy, say $\pi=\sigma\left(X_{1}\right)$, that maximizes the welfare of the consumers. The government's objective function is

$$
S\left(\sigma, E_{2} ; X_{1}\right)=U\left(C_{1}+C_{2}\left(X_{1}, \pi\right), L\left(X_{1}, \pi\right)\right)
$$

where $\pi=\sigma\left(X_{1}\right)$. Given $X_{1}$ and $F_{2}$, the government must select a policy $\sigma\left(X_{1}\right)$ that satisfies its budget constraint:

$$
g \leq \delta\left(X_{1}\right) R K+\tau\left(X_{1}\right) L\left(X_{1}, \sigma\left(X_{1}\right)\right)
$$

Let $\Sigma\left(\mathrm{F}_{2} ; \mathrm{X}_{1}\right)$ denote the set of all policies $\sigma\left(\mathrm{X}_{1}\right)$ that satisfy (2.5). The problem of the government is to pick a plan o such that for every $F_{1}, \sigma\left(X_{1}\right)$ maximizes utility (2.4) over the set of feasible policies $\Sigma\left(F_{2} ; X_{1}\right)$. 
Finally, consider the consumer's problem at the first stage. Each consumer chooses an individual allocation for the first stage, $x_{1}=\left(c_{1}, k\right)$, together with an allocation rule $f_{2}$ for taking actions at the second stage. Each consumer takes it as given that the current aggregate allocation is some $X_{1}$; future policy is set according to the plan $\sigma$; and future aggregate allocations are set according to some rule $F_{2}$. Given these assumptions the firststage competitive equilibrium is defined analogously to the second-stage competitive equilibrium and is summarized by $\left(\sigma, X_{1}, F_{2}\right)$.

We have recursively defined the consumer and the government problems. Combining these gives an equilibrium with sequential rationality built in for both the private agents and the government. Because of this, we say the equilibrium is time consistent. Formally,

A time consistent equilibrium is a triple $\left(\sigma, X_{1}, F_{2}\right)$ that satisfies

- Sequential rationality by consumers. $\left(\sigma, X_{1}, F_{2}\right)$ is a first-stage competitive equilibrium and, for every history $\left(\pi^{\prime}, X_{1}^{\prime}\right), F_{2}\left(\pi^{\prime}, X_{1}^{\prime}\right)$ is a second-stage competitive equilibrium.

- Sequential rationality by the government. Given $F_{2}$, the policy plan o solves the government's problem for every history $X_{1}^{\prime}$.

We then have the following proposition.

Proposition 3 (Single-period time consistent equilibrium)

The single-period time consistent equilibrium has first-stage al10cations $C_{1}=\omega$ and $K=0$ and a capital tax plan $\delta\left(X_{1}\right) \equiv 1$.

Proof. Consider first the policy plan $\sigma$. For any given first-stage aggregate allocation $X_{1}=\left(C_{1}, K\right)$, it is clearly optimal for the government to raise as much revenue as possible from taxing the given amount of capital. By assumption, $g>R \omega$ so that even if all the endowment is saved and the resulting 
capital is fully taxed, the revenues fall short of government spending. Thus, $\delta\left(X_{1}\right) \equiv 1$. Faced with such a tax, it is optimal for consumers to save nothing and consume all of their endowments. $\diamond$

It is easy to verify that the utility level of each consumer in the time consistent equilibrium is strictly lower than the level in the Ramsey equilibrium. An important question that remains is, what is the source of the conflict in this example? To investigate this question we cast our model in the general social choice framework considered in section 1. To accomplish this we need to embed the budget constraints of consumers and the government into preferences. Let the preferences of each private agent be given by

$$
U(\omega-k+(1-\delta) R k+(1-\tau) \ell, \ell)+W(K, L, \delta, \tau)
$$

where the function $W$ equals zero if its arguments $(K, L, \delta, \tau)$ satisfy the government's budget constraint, $g \leq \delta R K+\tau L$, and $W$ equals some large negative number otherwise. Notice, also, that we have assumed consumers are pricetakers, in the sense that they regard aggregates as being unaffected by their decisions. Thus, this model is a special case of the representative agent model considered in subsection 1.3 .

\subsection{A finite horizon model of capital taxation}

Consider a finite repetition of capital taxation model. To keep things simple we assume that capital cannot be stored between periods, that there is no borrowing and lending across periods, and that government spending is constant. With commitment, the government chooses a sequence of tax rates once and for all at the beginning of time. A competitive equilibrium is then a sequence of individual and aggregate allocations that maximize consumer welfare, clear markets, and satisfy representativeness. The Ramsey equilib- 
rium in this multiperiod model is simply the one-period Ramsey equilibrium repeated finitely many times.

Without commitment, the problem is more complicated because all decisions must be sequentially rational. Consumers must forecast how future tax rates will be chosen, and the government must forecast how its current choices influence future decisions of consumers. Following Chari-Kehoe (1987a and b) we resolve this forecasting problem by making allocations and policies functions of the history that constitutes the set of all past decisions. Formally, the history of an individual consumer at the first stage of period $t$ is

$$
h_{1 t}=\left(x_{s}, x_{s}, \pi_{s} \mid s=0, \ldots, t-1\right)
$$

Let $\mathrm{H}_{1 \mathrm{t}}$ denote the aggregate history at the first stage

$$
H_{1 t}=\left(X_{s}, \pi_{s} \mid s=0, \ldots, t-1\right) .
$$

Likewise, let $\mathrm{H}_{t}$ denote the aggregate history confronting the government after consumers have made their first stage decisions in period $t$ :

$$
H_{t}=\left(X_{s}, \pi_{s} \mid s=0, \ldots, t-1\right) \cup X_{1 t} \text {. }
$$

Note that the aggregate history does not include individual allocations. This is in keeping with the assumption that tax rates are the same across all consumers and cannot be altered by the decisions of any single consumer. At the second stage, a consumer's history records all decisions up to then and is given by

$$
h_{2 t}=\left(h_{1 t}, x_{1 t}, x_{1 t}, \pi_{t}\right)
$$


Likewise, the aggregate history at the second stage is

$$
H_{2 t}=\left(H_{1 t}, X_{1 t}, \pi_{t}\right)
$$

Allocations and policies are defined as functions of the histories. Let $f_{t}=\left(f_{1 t}, f_{2 t}\right)$ denote individual allocation functions which map first and second stage individual histories into decisions at the respective stages. Let $F_{t}=\left(F_{1 t}, F_{2 t}\right)$ denote the corresponding aggregate allocation function which maps aggregate histories into aggregate allocations. Let $\sigma_{t}$ denote the government's policy function which maps histories $H_{t}$ into decisions at $t$.

Now in order to define a time consistent equilibrium, we need to explain how allocation and policy functions induce future histories. In what follows, we consider only symmetric histories. Let $f^{t}=\left(f_{t}, f_{t+1}, \ldots\right)$ denote a sequence of individual allocation rules from $t$ onward. Let $F^{t}$ and $\sigma^{t}$ denote the corresponding objects for the aggregate allocation rules and policy plans. Given a history $h_{1 t}$, the functions $f^{t}, F^{t}$, and $\sigma^{t}$ induce individual histories as follows:

$$
\begin{aligned}
& h_{2 t}=\left\{h_{1 t}, f_{1 t}\left(h_{1 t}\right), F_{1 t}\left(H_{1 t}\right), \sigma_{t}\left(H_{1 t}, F_{1 t}\left(H_{1 t}\right)\right)\right\}, \\
& h_{1 t+1}=\left(h_{2 t}, f_{2 t}\left(h_{2 t}\right), F_{2 t}\left(H_{2 t}\right)\right)
\end{aligned}
$$

and so on. Likewise, from any initial aggregate history, say $\mathrm{H}_{1 t}$, the contingency plans $\mathrm{F}^{\mathrm{t}}$ and $\sigma^{t}$ induce future histories $\left(\mathrm{H}_{t}, \mathrm{H}_{2 t}, \mathrm{H}_{1 t+1}, \ldots\right)$ in a similar fashion.

Consider the first stage of period $t$. Given some history $h_{1 t}$, an individual consumer chooses a contingency plan $f^{t}$. Each consumer takes it as given that future aggregate allocations and policies will evolve according to the histories induced by $\mathrm{F}^{t}$ and $\sigma^{t}$. Recalling that we only consider symmetric histories, we have: 
A competitive equilibrium at the first stage of $t$, given a history $H_{1 t}$, is a set of contingency plans $f^{t}, F^{t}$, and $\sigma^{t}$ that satisfy:

- Consumer maximization. Given $\mathrm{H}_{1 t}, \mathrm{~F}^{t}$, and $\sigma^{t}$, the individual allocation rules $\mathrm{f}^{t}$ maximize

$$
\sum_{s=t}^{T} \beta^{s-t} U\left(c_{1 s}\left(h_{1 s}\right)+c_{2 s}\left(h_{2 s}\right), l\left(h_{2 s}\right)\right)
$$

subject to $c_{1 s}\left(h_{1 s}\right) \leq w-k_{s}\left(h_{1 s}\right)$

$$
c_{2 s}\left(h_{2 s}\right) \leq R\left[1-\delta_{s}\left(H_{s}\right)\right] k\left(h_{1 s}\right)+\left[1-\tau_{s}\left(H_{s}\right)\right] \ell\left(h_{2 s}\right)
$$

where for all $s \geq t$, the future histories are induced by $\mathrm{f}^{t}, \mathrm{~F}^{t}$, and $\sigma^{t}$.

- Government budget constraint. For all future histories induced by $F^{t}$ and $\sigma^{t}$,

$$
g \leq R \delta_{s}\left(H_{s}\right) K_{s}\left(H_{1 s}\right)+\tau_{s}\left(H_{s}\right) L_{s}\left(H_{2 s}\right) .
$$

- Representativeness. $f^{t}=F^{t}$.

We refer to this equilibrium as a pair $\left(\sigma^{t}, F^{t}\right)$. Likewise, a competitive equilibrium at the second stage of $t$, given a history $h_{2 t}$, is a set of contingency plans $\left(f_{2 t}, f^{t+1}\right),\left(E_{2 t}, F^{t+1}\right)$, and $o^{t+1}$ that satisfy conditions similar to those above. We refer to this equilibrium as $\left(\sigma^{t+1}, F_{2 t}, F^{t+1}\right)$.

Next consider the situation of the government in period $t$. Given some history $\mathrm{H}_{t}$ and taking it as given that future aggregate allocations evolve according to $\left(F_{2 t}, F^{t+1}\right)$, the government selects a policy plan $\sigma^{t}$ that maximizes consumer welfare. The government's objective function is

$$
\begin{aligned}
S_{t}\left(\sigma^{t}, F_{2 t}, F^{t+1} ; H_{t}\right)= & U\left(C_{1 t}+C_{2 t}\left(H_{2 t}\right), L_{t}\left(H_{2 t}\right)\right) \\
& +\sum_{s=t+1}^{T} B^{s-t_{U}}\left(C_{1 s}\left(H_{1 s}\right)+C_{2 s}\left(H_{2 s}\right), L_{s}\left(H_{2 s}\right)\right) .
\end{aligned}
$$


Given the history $H_{t}$ and the allocation rules $\left(F_{2 t}, F^{t+1}\right)$, the government must select a policy plan that not only satisfies its current budget constraint,

$$
g \leq \delta_{t}\left(H_{t}\right) R K_{t}+\tau_{t}\left(H_{t}\right) L_{t}\left(H_{2 t}\right)
$$

but also satisfies its future budget constraints,

$$
g \leq \operatorname{R\delta }\left(H_{s}\right) K_{s}\left(H_{1 s}\right)+\tau_{s}\left(H_{s}\right) L_{s}\left(H_{2 s}\right)
$$

for all aggregate histories induced by $\left(\mathrm{F}_{2 t}, \mathrm{~F}^{\mathrm{t}+1}\right)$ and $\sigma^{\mathrm{t}}$. Let $\Sigma_{t}\left(F_{2 t}, F^{t+1} ; H_{t}\right)$ be the set of all policy plans $\sigma^{t}$ that satisfy these budget constraints. The problem of the government at $t$, then, is to pick a plan $\sigma^{t}$ that maximizes consumer welfare (2.6) over the set of all feasible policies $\Sigma_{t}\left(F_{2 t}, E^{t+1} ; H_{t}\right)$.

Combining these various definitions gives us a type of equilibrium that will not "break down" as time evolves, since by construction the various contingency plans will be carried out for any possible set of histories. We have the following definition:

A time consistent equilibrium is a $(\sigma, F)$ pair that for each $t$ satisfies

- Sequential rationality by consumers. For every history $\mathrm{H}_{1 t}$, $\left(\sigma^{t}, F^{t}\right)$ is a first-stage competitive equilibrium. For every history $\mathrm{H}_{2 t}$, the triple $\left(\sigma^{t+1}, F_{2 t}, F^{t+1}\right)$ is a second-stage competitive equilibrium.

- Sequential rationality by the government. For every history $H_{t}$, the plan $\sigma^{t}$ maximizes consumer welfare over the set of feasible plans $\Sigma_{t}\left(F_{2 t}, F^{t+1} ; H_{t}\right)$.

We abbreviate notation and let $S_{0}(\sigma, F)$ denote the value of utility at time 0 in a time consistent equilibrium. 
It is easy to characterize time consistent equilibria using backward induction. At the second stage of the last period, the consumer's decision problem depends only upon current tax rates and the current capital stock; it is independent of the rest of the history. Consequently, the government's decision problem depends only upon the current capital stock. It follows that the equilibrium in the last period is identical to the single period equilibrium and is independent of the history. Next consider the problem in period T - 1. Clearly, neither the government's decisions nor private agents' decisions have any effect on outcomes in period $T$. Hence, the period $T-1$ problem is also static and the outcomes are identical to those in the singleperiod case.

Repeating this argument, it follows that for the finite horizon case, the time consistent equilibrium is unique and is simply the sequence of the single-period time consistent equilibria. As we will see in section 4 , in the infinite horizon case this backward induction argument cannot be used to characterize the set of time consistent equilibria, and the set of such equilibria is typically quite large.

\section{A finite horizon model of debt and default}

In the multiperiod capital taxation model of section 2 , we assumed that capital depreciated completely between periods and that agents could not borrow or lend. Technically, this implied that there were no state variables, like capital or debt, connecting one period to the next. In addition, we assumed a linear production function so that the calculation of equilibrium prices would be trivial. These features helped make our analysis of the model simple, and thus the model served as a useful introduction to multiperiod models with time consistency problems. In most macroeconomic models of interest, however, there are physical state variables and the calculation of equi- 
librium prices is nontrivial. The main goal of this section is to give an introduction to such models and to highlight some of the issues that arise. We accomplish this by studying a simple model of debt and default. A secondary goal is to show that even in this simple model it is a nontrivial problem to determine whether or not there is a time consistency problem. In particular, we show that while the conflicts among agents of the type considered in section 1 are necessary for a time consistency problem, they are not sufficient.

We consider a finite horizon model of debt similar to the models of Prescott (1977), Lucas and Stokey (1983), and Barro (1979). In particular, in the model government consumption fluctuates over time and the revenues to finance this consumption are raised through distortionary taxation of labor. The government is allowed to tax debt. Any tax on debt is interpreted a partial default and a 100 percent tax is interpreted as a complete default. For simplicity we assume there is no capital.

In the commitment equilibrium the government uses debt to smooth distortions from labor taxation over time. With a fluctuating stream of government consumption, this implies that the Ramsey policy will be not to balance the budget in each period. In the no-commitment equilibrium it is this lack of budget balance that drives the time consistency problem. In particular, without commitment whenever the outstanding government debt is positive, the government has an incentive to default on the debt in order to decrease the amount of distortionary labor taxation.

In this section we initially assume that the only type of debt is single-period debt. Lucas and Stokey (1983) consider a model similar to ours and allow for debt of all possible maturities. It is easy to show that with commitment there is no loss of generality in considering only one period debt 
in the sense that the Ramsey allocations when there is only one period debt coincide with the Ramsey allocations, when there is multiperiod debt. However as Lucas and Stokey show, without commitment restricting debt to be one period alters the set of allocations attainable in a time consistent equilibrium. For notational simplicity we explicitly write out the budget constraints only for the case of one-period debt. However, we characterize the time consistent equilibrium for the case of multiperiod debt.

\subsection{Debt and default with commitment}

Consider an economy populated by a large number of identical agents who live for $\mathrm{T}+1$ periods. In each period there are three goods: labor, a privately produced good, and a public good. A constant returns-to-scale technology is available to transform one unit of labor into one unit of output. The output can be consumed privately or used to provide a public good, referred to as government consumption. The per capita level of government consumption in each period, denoted $g_{t}$, is exogenously specified. Let $c_{t}$ and $l_{t}$ denote the individual levels of consumption and labor, and let $C_{t}$ and $L_{t}$ denote the aggregate (or per capita) values of these variables. An aggregate allocation $(C, L)=\left\{C_{t}, L_{t}\right\}_{t=0}^{T}$ is feasible if it satisfies

$$
C_{t}+g_{t}=L_{t}
$$

The preferences of each agent are given by

$$
\sum_{t=0}^{T} \beta t_{U}\left(c_{t}, l_{t}\right)
$$

where $U$ is strictly increasing, strictly concave, and bounded, and where $0<B$ $<1$.

Let $p_{t}$ denote the price of the consumption good at time $t$ in an abstract unit of account, and denote the vector of prices by $p=\left\{p_{t}\right\}_{t=0}^{T}$. 
Since the constant returns-to-scale technology transforms a unit of labor into one unit of output, the wage rate equals the price of the consumption good. We assume that revenues can be raised only through a proportional tax on labor income. Let $\tau_{t}$ denote the tax rate on the labor income earned in period $t$, and let $\tau=\left\{\tau_{t}\right\}_{t=0}^{T}$ denote the sequence of such tax rates. The budget constraint of the representative consumer is then

$$
\sum_{t=0}^{T} p_{t}\left[c_{t}-\left(1-\tau_{t}\right) e_{t}\right]=0 \text {. }
$$

Likewise, the government's budget constraint is

$$
\sum_{t=0}^{T} p_{t}\left[g_{t}-\tau L_{t}\right]=0 .
$$

Notice that we have written the consumer's budget constraint in "date 0 " or present-value form. Implicit in this constraint is a sequence of government debt held by consumers. To understand the government's incentives to $\operatorname{tax}$ (or to default) on the debt, it is useful to explicitly write out this sequence. Suppose, for simplicity, there is only single-period debt. Let $b_{t+1}$ denote the number units of government debt bought at $t$ by a consumer. Each such unit of debt represents a claim, before taxes, to one unit of the consumption good at period $t+1$. Denote the tax rate on such claims by $\delta_{t+1}$, so that then, after taxes, each unit is a claim to only $\left(1-\delta_{t+1}\right)$ units of the consumption good at $t+1$. The price of such a claim is then simply $p_{t+1}\left(1-\delta_{t+1}\right)$. Now suppose that at time $t, b_{t}$ units of the debt mature and the current consumption and labor supply are $c_{t}$ and $\ell_{t}$. Then (3.3) implies that new purchases of debt $b_{t+1}$ evolve according to

$$
p_{t}\left[c_{t}-\left(1-\tau_{t}\right) e_{t}\right]+p_{t+1}\left(1-\delta_{t+1}\right) b_{t+1}=p_{t}\left(1-\delta_{t}\right) b_{t} .
$$


That is, the value of an agent's consumption net of labor income plus new purchases of debt must add up to his outstanding net debt position. A similar law of motion holds for the aggregate level of debt,

$$
p_{t}\left[C_{t}-\left(1-\tau_{t}\right) L_{t}\right]+p_{t+1}\left(1-\delta_{t+1}\right) B_{t+1}=p_{t}\left(1-\delta_{t}\right) B_{t}
$$

Using the feasibility condition (3.1) and rearranging terms, we can rewrite this law of motion in the more familiar form,

$$
p_{t+1}\left(1-\delta_{t+1}\right) B_{t+1}=p_{t}\left(1-\delta_{t}\right) B_{t}+p_{t}\left[g_{t}-\tau_{t} L_{t}\right]
$$

We require that $B_{0}=0$ and $B_{T+1}=0$ so that the sequence of constraints (3.7) is equivalent to the government's present-value budget constraint (3.4). Likewise we require that for each agent, $b_{0}=0$ and $b_{T+1}=0$ so that the sequence of constraints (3.5) is equivalent to the agent's present-value budget constraint (3.3).

In this economy an individual agent's allocation is a vector of consumption, labor, and debt levels, denoted by $x=\left\{x_{t}\right\}_{t=0}^{T}$, where $x_{t}=$ $\left(c_{t}, e_{t}, b_{t+1}\right)$. An aggregate allocation is defined analogously and denoted by $x=\left(x_{t}\right)_{t=0}^{T}$ where $x_{t}=\left(C_{t}, L_{t}, B_{t+1}\right)$. A policy for the government is a sequence of tax rates on labor and on debt and is denoted by $\pi=\left\{\pi_{t}\right\}_{t=0}^{T}$ where $\pi_{t}=\left(\tau_{t}, \delta_{t}\right)$. We then have the following definition:

A competitive equilibrium is a set of individual allocations $x$, an aggregate allocation $X$, a price system $p$, and a policy $\pi$ that satisfy

- Feasibility. The aggregate allocation $X$ satisfies the feasibility condition (3.1) for each $t$.

- Consumer maximization. Given $\pi, p$, and $X$, the individual allocation $x$ maximizes utility (3.2) subject to the constraints (3.5) and $b_{0}=b_{t+1}=0$. 
- Government budget constraint. Given $\mathrm{p}$ and $\mathrm{X}$, the policy $\pi$ satisfies constraints (3.7) and $B_{0}=B_{t+1}=0$.

- Representativeness. $\mathrm{x}=\mathrm{x}$.

The feasibility condition together with the consumer's budget constraint imply the government's budget constraint. We include the latter constraint in the definition of equilibrium only for emphasis. Since in any equilibrium the individual and aggregate allocations coincide, we refer to such a competitive equilibrium as a triple $(\pi, X, p)$. Let $E$ denote the set of policies for which an equilibrium exists. Assume that for each $\pi$ in $E$ there is a unique allocation $X(\pi)$ and price system $p(\pi)$ associated with $\pi$. Let $S(\pi, X(\pi))$ denote the equilibrium value of utility under a policy $\pi$

$$
S(\pi, X(\pi))=\sum_{t=0}^{T} B^{t} U\left(C_{t}(\pi), L_{t}(\pi)\right) .
$$

We say $(\pi, X, p)$ is a Ramsey equilibrium if $\pi$ solves

$$
\max _{\pi \in E} S(\pi, X(\pi))
$$

and $X=X(\pi)$ and $p=p(\pi)$.

In this model we have allowed government to tax labor and debt. As we shall see in the no-commitment equilibrium, the incentive to use the tax on debt to renege on claims drives the time consistency problem. However, interestingly enough, in the Ramsey equilibrium the ability to tax debt is irrelevant and, in terms of allocations, all that really matters is the tax on labor. Specifically, the set of competitive equilibrium allocations in this model are identical to that in a model in which the government is prohibited from taxing debt. That is, if $(\pi, x, p)$ is an equilibrium with $\delta_{t}$ possibly positive for some $t$, then $(\hat{\pi}, \hat{x}, p)$ is also an equilibrium with $\hat{\tau}_{t}=0, \hat{\delta}_{t}=0$, $\hat{C}_{t}=C_{t}, \hat{L}_{t}=L_{t}$, and $\hat{B}_{t}=B_{t}\left(1-\delta_{t}\right)$ for each $t$. This result implies that the 
Ramsey allocations coincide with those of the standard optimal tax problem in which no default on debt is permitted. In particular, Chari and Kehoe (1987b) prove the following proposition:

\section{Proposition 4 (Ramsey equilibrium)}

The allocations $\left\{C_{t}, L_{t}\right\}_{t=0}^{T}$ in the Ramsey equilibrium solve the following problem

$$
\max \sum_{t=0}^{T} \beta^{t} U\left(C_{t}, L_{t}\right)
$$

subject to

$$
\begin{aligned}
& C_{t}+L_{t}=g_{t} \\
& \sum_{t=0}^{T} \beta^{t}\left[U_{c} C_{t}-U_{\ell} L_{t}\right]=0 .
\end{aligned}
$$

In this proposition the first set of constraints are simply the feasibility constraints while the second constraint is equivalent to the date 0 budget constraining of the government (3.4). To derive this we use the fact that in any competitive equilibrium, with the tax on debt identically zero, the consumer's first order conditions imply

$$
p_{t}=s^{t} U_{c}\left(C_{t}, L_{t}\right)
$$

and

$$
\left(1-\tau_{t}\right)=U_{e}\left(C_{t}, L_{t}\right) / U_{c}\left(C_{t}, L_{t}\right)
$$

\subsection{Debt and default without commitment}

In an environment without commitment, we can no longer retain the fiction that all agents make decisions once and for all at the beginning of time and then simply execute those decisions at the appropriate time. Indeed, 
we need to ensure that these decisions are sequentially rational. In terms of the timing of decisions, we model the sequential decision making by assuming that governments in each period choose a policy at the beginning of the period and then consumers choose their consumption and labor supply decisions. As in section 2, governments choose policies as a function of the aggregate history which for this model consists of the past aggregate consumption, labor, and debt-holding decisions and the past policies. Thus an aggregate history confronting the government at time $t$ is

$$
H_{t}=\left\{X_{s}, \pi_{s} \mid s=0, \ldots, t-1\right\} \text {. }
$$

Consumers make their choices over consumption, labor, and their debt holdings at date $t$ as functions of their individual histories. Such a history includes the policy choice $\pi_{t}$ as well as the past individual decisions, past aggregate decisions, and past policy choices. The history is given by

$$
h_{1 t}=\left\{x_{s}, x_{s}, \pi_{s} \mid s=0, \ldots, t-1\right\} \cup\left\{\pi_{t}\right\} .
$$

Finally, the aggregate histories $\mathrm{H}_{1 t}$ are

$$
H_{1 t}=\left\{x_{s}, \pi_{s} \mid s=0, \ldots, t-1\right\} \cup\left\{\pi_{t}\right\} .
$$

In keeping with the representative agent model used, we consider only symmetric histories.

For this environment a time consistent equilibrium consists of an individual allocation rule $f$, an aggregate allocation rule $F$, a policy plan $\sigma$, and a price system $p$ that satisfy certain sequential rationality conditions. An individual allocation rule is sequence of functions $f=\left\{f_{t}\right\}_{t=0}^{T}$ where $f_{t}$ maps each individual history $h_{1 t}$ into an agent's current choice of consumption, labor, and debt. Likewise, an aggregate allocation rule is a sequence 
of functions $F=\left\{F_{t}\right\}_{t=0}^{T}$, where $F_{t}$ maps each aggregate history $H_{1 t}$ into an aggregate amount of consumption, labor, and debt. A policy plan $\sigma$ is a sequence of functions $\sigma=\left\{\sigma_{t}\right\}_{t=0}^{T}$, where $\sigma_{t}$ maps each history $H_{t}$ into a current tax rate on labor and debt. Finally, a price system $p$ is a sequence of functions $p=\left\{p_{t}\right\}_{t=0}^{T}$, where $p_{t}$ maps each history $H_{t t}$ into a price level for the consumption good at $t$. Now just as in section 2, given any history $h_{1 t}$, the contingency plans $\mathrm{f}^{t}, \mathrm{~F}^{t}$, and $\sigma^{t}$ induce future individual histories. For example, an agent's history at time $t+1$ is

$$
h_{1 t+1}=\left\{h_{1 t}, f_{t}\left(h_{1 t}\right), E_{t}\left(H_{1 t}\right), \sigma_{t}\left(H_{1 t}\right)\right\}
$$

and so on. In a similar fashion, given any aggregate history the contingency plans $\mathrm{F}^{t}$ and $\sigma^{t}$ induce future aggregate histories in the obvious way.

In a time consistent equilibrium sequential rationality by consumers is modeled by assuming that the policy plans, allocation rules and price functions form a competitive equilibrium for each aggregate history. In this equilibrium each consumer is assumed to act competitively in that he assumes the evolution of policies and prices is uninfluenced by his actions. In particular, since future policies and prices are determined by aggregate histories, acting competitively implies that each consumer believes that his actions have no effect on aggregate histories.

The problem of the consumer at time to for some given functions $\mathrm{F}^{t}, \sigma^{t}, \mathrm{p}^{\mathrm{t}}$ and history $\mathrm{h}_{1 \mathrm{t}}$ is to maximize

$$
\sum_{s=t}^{\infty} \beta^{s-t_{U}}\left(c_{s}\left(h_{1 s}\right), l_{s}\left(h_{1 s}\right)\right)
$$

subject to the budget constraint

$$
\sum_{s=t}^{T} p_{s}\left(H_{1 s}\right)\left[c_{s}\left(h_{1 s}\right)-\left(1-\tau_{s}\left(H_{s}\right)\right) e_{s}\left(h_{1 s}\right)\right]=p_{t}\left(H_{1 t}\right)\left(1-\delta_{t}\left(H_{1 t}\right)\right) b_{t}
$$


and the law of motion for individual debt (3.5)

In such a competitive equilibrium the government's budget constraint is given by

$$
\sum_{s=t}^{\infty} p_{s}\left(H_{1 s}\right)\left[g_{s}-\tau s\left(H_{s}\right) L_{s}\left(H_{1 s}\right)\right]+p_{t}\left(H_{1 t}\right)\left(1-\delta_{t}\left(H_{t}\right)\right) B_{t}=0
$$

and the law of motion for government debt is given by (3.7). We then have the following definition:

A competitive equilibrium at date $t$ given a history $H_{t}$ is a sequence of individual and aggregate allocation rules $f^{t}$ and $F^{t}$, price functions $p_{t}$, and policy plans ot that satisfy:

- Feasibility. The aggregate allocation rule $F^{t}$ and $\sigma^{t}$ satisfy, for all $s \geq t, C_{s}\left(H_{1 s}\right)+g_{s}=L_{s}\left(H_{1 s}\right)$.

- Consumer maximization. Taking $F^{t}, p^{t}$, and $\sigma^{t}$ as given, $f^{t}$ solves the consumer's problem of maximizing (3.8) subject to (3.9) and (3.5).

- Government budget constraint. Given $F^{t}$ and $p^{t}$ the policy plan $\sigma^{t}$ satisfies the government budget constraint (3.10) and law of motion (3.7).

- Representativeness. $\mathrm{f}^{t}=\mathrm{F}^{\mathrm{t}}$.

It is important to note that in this definition the future histories $h_{1 s}, H_{1 s}$, and $\mathrm{H}_{\mathrm{s}}$ are induced by $\sigma^{t}, \mathrm{~F}^{t}$, and $\mathrm{p}^{t}$. Again we include the government's budget constraint only for emphasis. Since representativeness is part of the definition of equilibrium, we summarize any such equilibrium by the triple $\left(o^{t}, F^{t}, p^{t}\right)$.

Next consider the problem of the government. At time the government, faced with an aggregate history $H_{t}$, takes as given that future aggregate allocations and prices evolve according to the functions $F^{t}$ and $p^{t}$. It is 
important to note that in contrast to individual consumers the government can influence the future allocations and prices by affecting the aggregate history. The objective function of the government at $t$ is given by the utility of the representative agent from $t$ on under $F^{t}, p^{t}$, and $\sigma^{t}$, namely,

$$
s_{t}\left(\sigma^{t}, F^{t}, p^{t} ; H_{t}\right)=\sum_{s=t}^{T} \beta^{s-t_{U}}\left(C_{s}\left(H_{1 s}\right), L_{s}\left(H_{1 s}\right)\right) .
$$

The government choice set at time $t$ is the set of policy plans ot from $t$ onward that satisfy the government budget constraints (3.7) and (3.10) for all $s \geq t$. We denote this choice set by $\Sigma^{t}\left(F_{t}, p^{t}, H_{t}\right)$. For some aggregate histories $H_{t}$, this choice set may be empty and thus we restrict our attention to histories for which this set is not empty. ${ }^{1}$ Formally, we say a history $H_{t}$ is feasible under $\left(F^{t}, p^{t}\right)$ if $\Sigma^{t}\left(F^{t}, p^{t} ; H_{t}\right)$ is not empty. We then have, the following definition:

A time consistent equilibrium is a triple $(\sigma, F, p)$ that satisfies:

- Sequential rationality by consumers. For every feasible history $H_{t}$ under $\left(F^{t}, p^{t}\right)$, the triple $\left(\sigma^{t}, F^{t}, p^{t}\right)$ is a competitive equilibrium.

- Sequential rationality by the governments. For every feasible history $H_{t}$ under $\left(F^{t}, p^{t}\right)$, the policy plan $\sigma^{t}$ maximizes consumer welfare (3.13) over the $\operatorname{set} \Sigma^{t}\left(F^{t}, p^{t} ; H_{t}\right)$.

We can characterize the time consistent equilibria of this model using a backward induction argument. Recall that for the capital taxation model of section 2 we used such an argument to reduce the multiperiod time consistent equilibrium to a sequence of static equilibria. The key to that reduction was that there were no state variables connecting the periods. In this model government debt is such a state variable. This feature, together with the fact that government consumption fluctuates over time, implies that the time consistent equilibrium does not reduce so simply. Rather, the back- 
ward induction argument can be used to show that the time consistent equilibrium solves a constrained Ramsey problem in which debt issues are constrained to be nonpositive. Specifically, Chari-Kehoe (1987b) show that if debt of all maturities is allowed, the following proposition holds:

Proposition 5 (Time consistent equilibrium for the debt model)

The allocations in the unique time consistent equilibrium solve the constrained Ramsey problem.

$$
\max \sum_{t=0}^{T} \beta^{t} U\left(C_{t}, L_{t}\right)
$$

subject to

$$
\begin{aligned}
& C_{t}+g_{t}=L_{t} \\
& \sum_{t=0}^{T} B^{t}\left[U_{c} C_{t}-U_{l} L_{t}\right]=0
\end{aligned}
$$

and for all $\mathrm{s}=0,1, \ldots, \mathrm{T}$

$$
\sum_{s=t}^{T} B^{t-s}\left[U_{c} C_{s}-U_{\ell} L_{s}\right] \leq 0 .
$$

Notice that this problem is simply the Ramsey problem of Proposition 4 with the extra constraints (3.17). These constraints ensure that debt issues at each date are nonpositive.

The reason that the time consistent equilibrium solves such a problem is fairly intuitive. Consider the last period $T$. If the government inherits positive debt it clearly has an incentive to default in order to minimize the amount of revenue it must collect through a distortionary labor tax. However, if the government inherits negative debt, so that the government holds claims on private agents, it has no incentive to tax the debt. By induction it follows that for any period $t$, regardless of the history, the government will default on positive debt and not tax negative debt. 
We present several simple examples that illustrate the nature of the time consistent equiliorium. For these examples let autarky refer to the allocation obtained if the government has a continually balanced budget. The first example is one for which there is a time inconsistency problem: in it the unique time consistent equilibrium is autarky while the Ramsey equilibrium has a strictly positive level of debt.

Example 1: Let $T=1$, let $g_{0}=g>0$, and let $g_{1}=0$. It is easy to verify that under commitment the government optimally smooths distortions by running a deficit in date 0 . That is, the Ramsey tax level $\tau_{0}$ is such that $g_{0}-\tau_{0} L_{0}$ is strictly positive. Now consider the time consistent equilibrium. At date 1 if the history $H_{1}$ specifies some positive debt level, it is optimal for the government to default by setting $\delta_{1}^{\circ}=1$ and to set the labor tax $\tau_{1}$ to finance government. Given this, it is optimal for the government at date 0 to set $\tau_{0}$ so as to balance its budget; that is, so that $\tau_{0} \mathrm{~L}_{0}=\mathrm{g}_{0}$. Thus, by backward induction the unique time consistent equilibrium is autarky.

The second example is one for which there is no time consistency problem at all. In it the Ramsey allocations are time consistent.

Example 2: Let $T=1$, let $g_{0}=0$, and let $g_{1}=g>0$. In the Ramsey equilibrium the government optimally smooths distortions by setting positive labor taxes in both periods. Thus the government runs a surplus at date 0 , since $g_{0}-\tau_{0} L_{0}$ is strictly negative, and it "sells" negative debt into date 1 . Now consider the time consistent equilibrium. If at date 1 the history $H_{1}$ specifies a negative debt, the government clearly has no incentive to default and for such histories it sets $\delta_{1}=0$. (Of course, for any history $H_{1}$ with a positive debt, the government will default by setting $\delta_{1}=1$. ) Given this, it is optimal for the government at date 0 to set taxes at the Ramsey levels and 
to "sell" the appropriate amount of negative debt to consumers. At date 1 the government, faced with such a history, sets second-period taves at the Ramsey levels. Thus the unique time consistent equilibrium is identical to the Ramsey equilibrium, and hence there is no time consistency problem.

From the two previous examples one may mistakenly conclude that there are only two types of time consistent equilibria, namely, ones with a continuous balanced budget or ones in which there is no time consistency problem at all. We present a third example in which the time consistent equilibrium is neither autarky nor the time consistent equilibrium. In a sense this example represents the typical case.

Example 3: Let $\mathrm{T}=3$, let $\mathrm{g}_{0}=\mathrm{g}_{2}=\mathrm{g}>0$, and let $\mathrm{g}_{1}=\mathrm{g}_{3}=0$. Here the Ramsey equilibrium is simply the Ramsey equilibrium of example 1 repeated twice. In it debt issues are positive at dates 0 and 2 and thus the equilibrium is not time consistent. Consider the time consistent equilibrium. In order to smooth taxes at all between 2 and 3 the government must sell positive debt at date 2. Thus the time consistent policy must specify no debt issue at date 2. Notice, however, that the government can smooth taxes between dates 1 and 2 by selling negative debt at date 1 . Indeed in a time consistent equilibrium taxes between dates 1 and 2 are optimally smoothed with the same debt pattern as in example 2 and the government's budget is balanced at dates 0 and 3. This time consistent equilibrium is worse than the Ramsey equilibrium but better than autarky.

So far we have used this model of debt to illustrate what the computation of a time consistent equilibrium is like for a model with state variables. In addition we can use this model to illustrate how to map models with state variables (and nontrivial equilibrium prices) into a social choice 
framework similar to that of section 1. Recall that in that framework the preferences of each agent are defined directly as functions of the decisions of all agents. In particular, there were no prices or budget constraints.

The first step in putting this model into a social choice framework is to express prices as a function of agents decisions. It will prove convenient to work with the relative prices between periods instead of the original prices $\left\{p_{t}\right\}$. In particular for each period $t$ let $q_{t}=p_{t+1} / p_{t}$ be the relative price of the consumption good in $t$ and $t+1$. This relative price expressed as a function of agents' decisions is

$$
q_{t}=\frac{B U_{c}\left(L_{t+1}-g_{t+1}, L_{t+1}\right)}{U_{c}\left(L_{t}-g_{t}, L_{t}\right)} \text {. }
$$

Next we incorporate the sequence of budget constraints for private agents (3.5) and for the government (3.7) into preferences by defining preferences of private agents at period $t$ by

$$
\begin{aligned}
v_{t}\left(x_{t}, x_{t}, \pi_{t}, x_{t+1}, \pi_{t+1}\right)= & U\left(\left(1-\delta_{t}\right) b_{t}-q_{t}\left(1-\delta_{t+1}\right) b_{t+1}+\left(1-\tau_{t}\right) e_{t}, e_{t}\right) \\
& +W\left(\tau_{t} L_{t}-\left(1-\delta_{t}\right) B_{t}+q_{t} B_{t+1}\right)
\end{aligned}
$$

where the function $W$ equals zero if its arguments satisfy the government's budget constraint,

$$
g_{t} \leq \tau_{t} L_{t}-\left(1-\delta_{t}\right) B_{t}+q_{t+1} B_{t+1}
$$

and $W$ equals some large negative number otherwise. Preferences for the government at $t$ are

$$
S_{t}\left(x_{t}, \pi_{t}, x_{t+1}, \pi_{t+1}\right)=v_{t}\left(x_{t}, x_{t}, \pi_{t}, x_{t+1}, \pi_{t+1}\right)
$$


For both private agents and the government, preferences over the entire horizon are the discounted sum of preferences for each period $t$. Of course, to ensure that the two sequences of budget constraints incorporated in preferences are equivalent to the date 0 budget constraints (3.3) and (3.4) we also impose that initial and terminal debt positions be zero for both the private agents and other government, so that $\mathrm{b}_{0}, \mathrm{~b}_{\mathrm{T}+1}, \mathrm{~B}_{0}$, and $\mathrm{B}_{\mathrm{T}+1}$ are all equal to zero. Thus, from this representation it is clear that the debt and default model is simply a dynamic version of the representative agent problem considered in section 1 .

In this section we have accomplished three goals. First, we have shown how the introduction of state variables complicates the computation of time consistent equilibria. Second, we have shown that the presence of conflict among agents does not guarantee there is a time consistency problem. Finally, we have shown how to map dynamic models into our social choice framework.

\section{The infinite horizon}

So far we have analyzed finite horizon models of capital and debt. In this section we analyze infinite horizon version of these models. Our analysis will be somewhat brief. For details see Chari and Kehoe (1987a, 1987b).

With commitment the characterization of equilibrium is straightforward. For both models the infinite horizon Ramsey equilibria are unique. Furthermore, these equilibria are the limits of sequences of finite horizon Ramsey equilibria. For the capital model this implies that the infinite horizon Ramsey equilibrium is simply the one-period Ramsey equilibrium of Proposition 2 repeated forever. 
Without commitment the way to characterize the set of equilibria is not obvious. One way to proceed is to simply take the limits of a sequence of finite horizon time consistent equilibria. This technique will indeed yield a time consistent equilibrium. However, there are many other time consistent equilibria which are not limits of any sequence of finite horizon equilibria. In fact the set of time consistent equilibria is very large and difficult to characterize. However, it is relatively easy to characterize the policies and allocations induced by time consistent equilibria.

Recall that, in general, a time consistent equilibrium $(\sigma, F, p)$ is a sequence of functions which specify policies, allocations, and prices for all possible histories. Starting from the null history at date 0 a time consistent equilibrium induces a particular sequence of policies, allocations and prices, say $(\pi, X, p)$. We call this the outcome induced by the time consistent equilibrium.

The technique for characterizing the set of such outcomes builds upon Abreu's (1984) seminal work in repeated games. In our models agents behave competitively rather than strategically and thus we need to reformulate Abreu's arguments. We first prove that a sequence of policies, allocations, and prices can be induced by some time consistent equilibrium if and only if can be induced by a particular time consistent equilibrium called the revert to autarky equilibrium. We use this result to show that an arbitrary sequence is an outcome of a time consistent equilibrium if and only if it satisfies two conditions. First, this sequence is a competitive equilibrium at date 0 . Second, this sequence must satisfy a certain set of simple inequalities..

In this section we concentrate on showing how these techniques work for the capital model, commenting only briefly on how they work for the debt model. 


\subsection{Capital taxation}

We proceed in two steps. First, we define the autarky equilibrium. Then we define the revert to autarky equilibrium. We use these to prove that an arbitrary sequence of policies and allocations can be induced by some time consistent equilibrium if and only if it can be induced by the revert to autarky equilibrium. We use this result to provide a simple characterization of time consistent policies and allocations.

The autarky equilibrium $\left(\sigma^{a}, F^{a}\right)$ is defined as follows. For the government the plan $\sigma_{t}^{a}\left(H_{t}\right)$ specifies the single-period time consistent plan of Proposition 3 regardless of the history up until time $t$. For private agents the allocation rules $\mathrm{F}_{1 \mathrm{t}}^{\mathrm{a}}\left(\mathrm{H}_{1 \mathrm{t}}\right)$ and $\mathrm{F}_{2 \mathrm{t}}^{\mathrm{a}}\left(\mathrm{H}_{2 t}\right)$ specify the single-period time consistent allocation rules regardless of the history up until time $t$. It is easy to verify that these policy plans and allocation rules constitute a time consistent equilibrium. Chari-Kehoe (1987a) prove the following:

Proposition 6 (Autarky is the worst time consistent equilibrium)

Any time consistent equilibrium $(\sigma, F)$ must have a utility level $S(\sigma, F)$ greater than or equal to the utility level $S\left(\sigma^{a}, F^{a}\right)$ of the autarky equilibrium.

Proof. We sketch the proof here. To establish the proposition we show for an arbitrary equilibrium $(\sigma, F)$, the following inequalities hold

$$
S(\sigma, F) \geq S\left(\sigma^{a}, F\right) \geq S\left(\sigma^{a}, F^{a}\right) \text {. }
$$

Both inequalities rely on a fact about competitive equilibria: For any period $t$ the second stage labor supply and consumption decisions solve the same static problem. From this fact it follows that a deviation by the government from $\sigma$ to $\sigma^{a}$ is feasible in that $\sigma^{a}$ satisfies the government budget constraint for any equilibrium allocation rule F. Sequential rationality by the government then yields the first inequality. 
Next, if the allocation rule $F$ specifies positive savings at some date $t$ the second equality holds since distorting taxes are Jeing replaced by lump sum taxes. If the rule $F$ specifies zero savings for all dates, the resulting allocations under $F$ and $F^{a}$ are identical. $\diamond$

The next proposition uses a modified version of the autarky plans called the revert to autarky plans. For an arbitrary sequence of policies and allocations $(\pi, X)$ the revert to autarky policy plans and allocation rules $\left(\sigma^{r}, F^{r}\right)$ specify continuation with the candidate sequences $(\pi, X)$ as long as they have been chosen in the past, otherwise revert to the autarky plans $\left(\sigma^{a}, F^{a}\right)$. Thus, for example, at time $t$ given a history $H_{t}$ this policy plan specifies: choose the tax rates $\pi_{t}$ specified by $\pi$ and the allocations $\left(x_{0}, x_{1}, \ldots, x_{t}\right)$ and $x_{1 t}$ have been chosen according to $x$. If they have not then revert to the autarky tax rule $\sigma^{a}$. The revert to autarky allocation rules $\mathrm{F}^{r}$ are similarly defined.

Consider then some arbitrary sequences $(\pi, X)$ and the associated revert to autarky plans. It will be useful to define the single period utility when the government reverts to autarky. Given that the first stage allocations $X_{1 t}$ at time $t$ have been chosen according to $X$ let $U^{d}\left(X_{1 t}\right)$ be the maximized value of utility under the autarky rule. It is easy to show

$$
U^{d}\left(X_{1 t}\right)=\max _{\left(\tau, C_{2}, L\right)} U\left(C_{1 t}+C_{2}, L\right)
$$

subject to

$$
\begin{aligned}
& C_{2} \leq(1-\tau) L \\
& \frac{U_{\ell}}{U_{c}}=(1-\tau) \\
& g \leq R K_{t}+\tau L .
\end{aligned}
$$


We then have the following proposition:

Proposition 7 (Time consistent equilibrium outcomes)

An arbitrary pair of sequences $(\pi, X)$ is the outcome of a time consistent equilibrium if and only if

$$
(\pi, X) \text { is a competitive equilibrium at date } 0 \text {. }
$$

(ii) for every $t$ the following inequality holds

$$
\sum_{S=t}^{\infty} B^{s-t} U\left(X_{s}\right) \geq U^{d}\left(X_{1 t}\right)+\frac{\beta}{1-\beta} U\left(X^{a}\right)
$$

where $x^{a}$ denotes the autarky equilibrium allocation.

Proof. Suppose first that $(\pi, X)$ is the outcome of a time consistent equilibrium $(\sigma, F)$. Sequential rationality of consumers requires that $(\pi, X)$ be a competitive equilibrium at date 0 . By an argument similar to the one in Proposition 6 a deviation by the government to the autarky plan $\sigma^{a}$ is feasible. Also, by Proposition 6, the autarky equilibrium is the worst equilibrium. Clearly then the utility of the government must be at least as large as the right-side of (4.2) for every period t.

Next, suppose some arbitrary pair of sequences $(\pi, X)$ satisfies (i)

and (ii). We need to show the associated revert to autarky plans $\left(\sigma^{r}, F^{r}\right)$ constitute a time consistent equilibrium. Consider histories under which there has been no deviations from $(\pi, X)$ up until t. Some $(\pi, X)$ is a competitive equilibrium at date 0 it is clear that its continuation from date $t$ is also a competitive equilibrium. This proves that sequential rationality for consumers is satisfied for such histories. Consider the situation of the government. Confronted with allocation rules $F^{r}$ the highest utility it can obtain from any deviation is given by the right-side of (4.2). This proves that $\sigma^{r}$ is sequentially rational for the government for such histories. 
Consider now histories for which there has been a deviation before time $t$. The revert to autarky rules $\left(a^{r}, F^{r}\right)$ specify autarky from then onwards. Clearly the autarky policies and allocations constitute a competitive equilibrium at $t$. Finally, faced with the autarky allocation rule it is optimal for the government to choose the autarky policy. Thus $\left(\sigma^{r}, F^{r}\right)$ is a time consistent equilibrium. $\diamond$

An immediate corollary to this proposition is a result which resembles the Folk theorem for repeated games (see, for example, Fudenberg and Maskin, 1986).

\section{Proposition 8}

There is some discount factor $\underline{\beta} \in(0,1)$ such that for all $\beta \in(\underline{\beta}, 1)$ the Ramsey allocations can be supported by a time consistent equilibrium.

Proof. Recall that the Ramsey allocations are the same in all periods. Denote the Ramsey allocation of any period by $X^{*}$. By Proposition 7 we need only verify that inequality $(4.2)$ is satisfied by $X^{*}$. Rearranging terms, we need to show

$$
\frac{\beta}{1-\beta}\left[U\left(X^{*}\right)-U\left(X^{a}\right)\right] \geq\left[U^{d}\left(X_{1}^{*}\right)-U\left(X^{*}\right)\right]
$$

Since the Ramsey allocations yield a strictly higher level of utility then the autarky allocations the left-side of (4.3) is positive. Since the left-side of (4.3) increases monotonically to infinity as the discount factor approaches one the proposition follows. $\diamond$

Proposition 7 and 8 have shown that the set of time consistent equilibria for the infinite horizon is much larger than the limit of the finite horizon equilibria. The result depends critically on the fact that 
both policy and allocation rules were allowed to depend on histories. If either of these rules were restricted not to depend on the history prior to the current period then the unique time consistent equilibrium is the limit of the finite horizon equilibrium. We see no compelling reason to restrict attention to such rules.

Results similar to ours are well-known for repeated games. However our models differ in an important aspect from repeated games. Private agents behave competitively rather than strategically. For exampie, in the revert to autarky equilibrium, consumers do not "punish" the government when it deviates. Rather they choose the autarky allocations because taking the future aggregate allocations and policies as outside of their control it is optimal to choose these allocations.

\subsection{Debt and default}

Analogues of Propositions 6 and 7 are proved in Chari-Kehoe (1987a). Here we sketch some of their arguments. The autarky equilibrium for this example is the limit of the finite horizon solutions given in Proposition 5. Thus, the worst time consistent allocations solve the constrained Ramsey problem. The revert to autarky equilibrium is defined as follows. In the event of any deviation, we must consider two situations. First, if the inherited debt is positive, default on the debt and solve the constrained Ramsey problem from then on. If the debt is negative, accept these claims on consumers and solve the associated constrained Ramsey problem. For an arbitrary sequence of policies, allocations and prices, we can use the revert to altarky rules to establish inequalities analogous to those in (4.2). However, unlike the capital taxation model the right-side of these inequalities will vary with the level of debt as well as with the pattern of government assumption. 
The most striking difference between the capital and the debt models is that Proposition 8 no longer holds in general in the debt model. For example, suppose that government consumption is positive in the initial period and zero forever thereafter. The Ramsey policies specify positive tax rates in all periods. However, in a time consistent equilibrium, the government always defaults on positive inherited debt. The unique time consistent equilibrium has a balanced budget in the initial period. Since this reasoning is independent of the discount factor, the Ramsey allocations are not the outcome of a time consistent equilibrium no matter how close the discount factor is to unity.

\section{Conclusions}

There is a large and growing body of literature on the time consistency problem and its implications for macroeconomic policy. In this paper we have sought to provide a perspective on the issue of time consistency rather than to survey the literature. In our view, conflict among agents plays a central role in creating time consistency problems. Because much of the literature has used representative agent models, the nature of this conflict has been obscured. We have shown how two representative agent models (of capital taxation and of debt and default) can be cast into a social choice theoretic framework in which the nature of this conflict is made explicit. Optimal taxation models, where revenues are raised through distorting taxes, necessarily share the feature that each agent is better off by forcing others to bear a larger share of the burden of providing public goods. This conflict plays an essential role in establishing that the timing of policies matters for allocations.

We have also provided a careful definition of time consistent equilibria for the capital taxation and debt and default models. Correctly de- 
fining a time consistent equilibrium requires that we consider history-contingent allocation and price functions. These are essential to ensure that the forecasting problems of policymakers and agents are well-defined. For the capital taxation example, we have also provided a complete characterization of the time consistent equilibria with an infinite horizon. The set of time consistent equilibria with an infinite horizon is substantially larger than with a finite horizon. Indeed, sometimes it is possible to sustain commitment equilibrium allocations as time consistent equilibria.

We should reemphasize that there is no sense in which societies can choose between commitment or time consistent equilibria. Commitment technologies are like technologies for making shoes in an Arrow-Debreu model--they are either available or not. In particular, commitment technologies are not objects of choice. This fact has important implications for the debate over rules versus discretion.

There is a temptation to view rules as describing policies chosen under commitment and discretion as describing policies chosen without commitment. Under our interpretation, societies cannot choose between commitment and no commitment. Consequently, societies cannot choose between rules and discretion. However, we think there are deeper issues in this debate. We have described policies here as being chosen by society, but actual policy choices must necessarily be delegated to specific institutions or individuals. Society's problem, then, is more than a choice from alternative policy rules; rather, the problem is to design the process by which policies are chosen. Formally, this is a problem in mechanism design. (See, for example, Hurwicz 1973, Myerson 1979, and Harris and Townsend 1981.) Erom this perspective, the debate over rules versus discretion is over how much authority should be delegated to policymakers. Research directed at integrating the 
issues of mechanism design into aggregative models is essential if we are to progress further in this debate. 


\section{Footnote}

${ }^{1}$ Consider, for example, a two-period version of this model such that first-period government consumption is zero and second-period government consumption is higher than the maximal amount of revenue that can be raised through a second-period labor tax (but small enough to be financed by a labor tax in both periods). Now suppose that in the second period the aggregate history specifies a zero tax on labor at the first date. Then by assumption there is no policy that could meet the government's budget constraint, so the government choice set would be empty. 
References

Abreu, Dilip. 1984. Infinitely Repeated Games with Discouncing: A General Theory. Harvard University Discussion paper no. 1083.

Barro, Robert J. 1979. On the Determination of the Public Debt. Journal of Political Economy 87.

- 1985. Record Developments in the Theory of Theory of Rules

Versus Discretion. University of Rochester working paper no. 12.

Barro, Robert J., and David B. Gordon. 1983a. Rules, Discretion and Reputation in a Model of Monetary Policy. Journal of Monetary Economics.

Calvo, Guillermo A. 1978. On the Time Consistency of Optimal Policy in a Monetary Economy. Econometrica 46.

Chari, V. V., and Patrick J. Kehoe. 1987a. Sustainable Plans. Federal Reserve Bank of Minneapolis working paper 377.

- 1978b. Sustainable Plans and Debt. Federal Reserve Bank of Minneapolis 354 .

Fischer, Stanley. 1980. Dynamic Inconsistency, Cooperation, and the Benevolent Dissembling Government. Journal of Economic Dynamics and Control 2.

Friedman, James W. 1971. A Non-cooperative Equilibrium for Supergames. Review of Economic Studies 38 .

Fudenberg, Drew, and Eric Maskin. 1986. The Folk Theorem for Repeated Games with Discounting or with Incomplete Information. Econometrica 54.

Harris, Milton, and Robert Townsend. 1981. Resource Allocation Under Asymmetric Information. Econometrica 49.

Hurwicz, Leonid. 1973. The Design of Mechanisms for Resource Allocation. American Economic Review 63.

Kydland, Einn E., and Edward C. Prescott. 1977. Rules Rather Than Discretion: The Inconsistency of Optimal Plans. Journal of Political Economy, 85. 
Lucas, Robert E., Jr., and Nancy L. Stokey. 1983. Optimal Fiscal and Monetary Policy in an Economy Without Capital. Journal of Monetary Economics 12.

Myerson, Roger. 1979. Incentive Compatibility and the Bargaining Problem. Econometrica 47.

Prescott, Edward C. 1977. Should Control Theory be Used for Economic Stabilization?. K. Brunner and A. H. Meltzer, eds., Optimal policies, control theory and technology exports (North-Holland, Amsterdam).

Ramsey, F. P. 1927. A Contribution to the Theory of Taxation. Economic Journal 37 .

Rogoff, Kenneth. 1988. Reputation, Coordination, and Monetary Policy. This handbook.

Strotz, Robert H. 1955. Myopia and Inconsistency in Dynamic Utility Maximization. Review of Economic Studies 23. 
